\title{
A BIOMIMÉTICA COMO FERRAMENTA NA REVITALIZAÇÃO DE AMBIENTES DE ESTUDO E PESQUISA: CASO DO INTECHLAB
}

Isla Vitória Carvalho Lopes - islavcl@yahoo.com.br

Maria Clara Cazita Soares Silva - mariaclaracazita@gmail.com

Centro de Educação Tecnológica de Minas Gerais, Técnico em Edificações - Campus II

Av. Amazonas 7675 - Nova Gameleira

30510-000 - Belo Horizonte - MG

Luciana Patrícia Ferreira - lupiferreira@ cefetmg.br

Centro de Educação Tecnológica de Minas Gerais, Departamento de Engenharia Civil e Meio Ambiente - Campus X

Rua Raymundo Mattoso, 900 - Santa Rita

35790-000 - Curvelo - MG

Mariana Martins Drumond - mmdrumond@ cefetmg.br

Centro de Educação Tecnológica de Minas Gerais, Departamento de Ciências Biológicas Campus I

Av. Amazonas, 5253 - Nova Suíça

30421-160 - Belo Horizonte - MG

Resumo: O crescimento na produção de pesquisas nas universidades e sua tendência à interdisciplinaridade e inovação ampliaram a demanda por espaços com perfil técnico, que sejam multifuncionais e versáteis. A Biomimética surge nesse sentido, uma vez que, aplicada ao design de interiores, permite expandir o conceito de imitação (mimes) da vida (bio) ao aspecto do habitat, ou seja, do espaço de suporte, e contribui na busca por produtividade com qualidade. $O$ objetivo deste trabalho é apresentar uma investigação projetual, a partir da Biomimética, de requalificação do espaço denominado IntechLab, Laboratório de Tecnologias Integradas CEFET-MG, com a demanda de conjugar duas vertentes de estudos, bioquímica e prototipagem, em um espaço que fomente a inovação e produtividade. A partir do programa de necessidades e do levantamento de informações, foi possível preparar o diagnóstico. A proposta foi delineada, apresentada e aprimorada a partir de reuniões com os usuários, resultando em projeto, instruções de implantação gradual e especificações. $O$ projeto ainda está em implantação, porém foi muito bem recebido e espera-se dar sequência à avaliação pós ocupação com análise da extensão do impacto da aplicação da metodologia Biomimética em oferecer soluções que, além de interativas e versáteis, sejam, também, mais humanas.

Palavras-chave: Espaços de Pesquisa. Biomimética. Arquitetura de Interiores. 


\section{INTRODUÇÃO/JUSTIFICATIVA}

O desenvolvimento de pesquisas e estudos com eixo na inovação, redirecionaram o foco dos ambientes acadêmicos. O caráter multidisciplinar das temáticas de pesquisa mostrou a necessidade de tornar o ambiente acadêmico um lugar integrado e de modificar o padrão construtivo desses locais. Por isso, a revitalização deve ser pautada na correção de problemas de conforto, ergonomia, iluminação e na relação do ser humano com o ambiente. Para isso, a Biomimética se traduz como uma solução na organização espacial e na reconexão do homem com a natureza, de forma direta e indireta, nesses ambientes, resultando em benefícios no rendimento e criatividade dos usuários.

Segundo Wilson (1984), o homem possui uma relação inata com a natureza e, por isso, deve manter-se conectado a ela. De acordo com Harkness (2002), o conceito de Biomimética foi definido por Otto H. Schmidt (1913-1998), como uma nova ciência cujo objetivo era estudar e replicar os métodos, projetos e processos da natureza. Ao incorporar esse conceito na arquitetura de interiores, ele se converte na possibilidade de edificações utilizarem essa ciência para promover uma integração da natureza, de forma não intrusiva ao local, e para possibilitar uma relação harmônica do ser humano com o ambiente ao conectá-lo com a natureza.

O tema surgiu a partir da revitalização do laboratório de tecnologias integradas, IntechLab, em funcionamento no Campus VI do CEFET-MG, localizado em Belo Horizonte. O local, um edifício antigo, precisava de intervenções e instalação segura de equipamentos direcionados a pesquisas de caráter interdisciplinar, ao mesmo tempo em que deveria manter sua versatilidade, mirando em outras prospecções de pesquisa. Outro desejo dos usuários era que o espaço permitisse interações e traduzisse a dinâmica de acolhimento presente no grupo em ambientes onde a prioridade fosse o ser humano, seu conforto físico e mental. Neste sentido, tanto a proposta de novas ferramentas quanto a aplicação de ferramentas já consagradas no design de interiores e na arquitetura foram aplicadas dentro de uma perspectiva Biomimética, na qual o espaço é entendido enquanto extensão do hábitat humano. Assim, espaços, fluxos e funções no laboratório se conformam para dar prioridade ao humano, respeitando necessidades biológicas para o desenvolvimento da atividade intelectual e física. Materiais e texturas, iluminação e ventilação, inclusive a adoção de paisagismo interior, podem ser aplicados de modo a gerar conforto psicológico e acolhimento.

\section{REVISÃO TEÓRICA}

\subsection{Biomimética}

O conceito de Biomimética vem do desmembramento do termo, que vem do grego, no qual bios significa vida, e mimesis, imitação. Esse conceito parte do pressuposto de que a natureza pode servir de referência para a construção das invenções humanas e foi criado pelo engenheiro biomédico da Universidade de Minnesota, Otto Herbert Schmitt, em 1957. A Biomimética vem surgindo como uma alternativa para solucionar problemas, em inúmeras áreas da ciência, por meio da utilização de soluções biológicas e sustentáveis como inspiração.

Essa formulação começou a ser abordada em 1997, no livro "Biomimética - Inovação Inspirada pela Natureza" de Janine Benyus. O livro apresenta histórias de algumas inovações, em diferentes campos do conhecimento, que foram arquitetadas através da observação da natureza. Essa técnica busca observar a natureza, por meio de diferentes perspectivas, com o intuito de imitar as soluções e empregá-las no cotidiano. Benyus (1997) apresenta três abordagens distintas para a utilização da Biomimética como ferramenta: a natureza como modelo, a natureza como medida e a natureza como mentora. 
Em todos os casos é utilizada a observação de processos e padrões da natureza para aplicálos diretamente ou para utilizar de inspiração em processos construtivos ou criação de produtos.

Ao adotar a prática da Biomimética, torna-se necessário sair de uma área de conforto, visto que é preciso assumir uma perspectiva multidisciplinar para visualizar as suas possíveis aplicações. Ela tem o intuito de funcionar como os ecossistemas, mantendo uma economia circular, que define que os produtos devem ter um ciclo completo para evitar desperdícios.

\subsection{Ferramentas Biomiméticas na Arquitetura e no Design de Interiores}

A utilização da natureza como modelo de estudo e inspiração para fornecer soluções para os problemas encontrados ou gerados nas construções humanas, por meio de respostas que serão biológicas e sustentáveis, resulta em diversas ferramentas, que são chamadas ferramentas Biomiméticas para o desenho de interiores. Essas ferramentas, que surgem a partir da associação da Biomimética com outros conceitos como ergonomia, conforto lumínico e térmico e materiais biológicos, servem para oferecer soluções para o sistema como um todo, trabalhando o espaço físico, bem como as necessidades humanas básicas e também a harmonização entre as pessoas e o ambiente.

Como ferramenta Biomimética, a ergonomia trabalha, partindo da afirmação de Vidal (2012), a fisiologia do trabalho (o funcionamento de nossos sistemas fisiológicos em diversos regimes), a psicologia experimental (a percepção de sinais, a discriminação de indícios, a legibilidade de instrumentação), a higiene e a toxicologia (os riscos envolvidos nas atividades). No cenário atual, a ergonomia física, definida por Vidal (2012) como o foco da ergonomia sobre os aspectos físicos de uma situação de trabalho, é essencial para solucionar problemas decorrentes dos móveis inadequados e das posições de trabalho dos usuários dos laboratórios.

Trabalhando o conforto da edificação, a Biomimética se traduz em elementos naturais e materiais que possam solucionar problemas já existentes. O conforto acústico de uma edificação é essencial para que ela se relacione positivamente com seus usuários, uma vez que ele influencia no bem-estar e condiciona fortemente a saúde e a produtividade. Para conforto acústico, a NBR 10.152 (1987) coloca os valores aceitáveis de níveis de ruídos para cada ambiente. Para a concepção de um projeto com bom desempenho acústico, a arquitetura do local que deve ser pautada em fatores como materiais empregados em sua construção, bem como a utilização dos espaços e as necessidades de seus futuros ocupantes.

Ademais, o conforto lumínico é importante para garantir que as funções e os sentidos do corpo humano trabalhem para realizar tarefas diárias, reduzindo os riscos de acidentes e danos a saúde, mantendo a forma mais adequada de trabalho. Cavalcanti (2002) afirma que a iluminação de um ambiente deve ser fundamentada não só nas questões quantitativas e econômicas, mas também nos benefícios físicos e psicológicos que ela gera sobre o organismo humano, podendo gerar um aumento na produtividade através da melhoria da qualidade do ambiente. Além da iluminação natural oferecida pela luz solar, a Biomimética surge como alternativa aplicando um processo natural para gerar iluminação em lâmpadas, substituindo a iluminação artificial. O BioLED, pelo fenômeno da bioluminescência, utiliza bactérias e algas para gerar iluminação, com o intuito de reduzir o consumo de energia bem como os resíduos que esse sistema produz.

A Biomimética pode ser aproximada desde forma, função e processo, conforme mostra a Figura 1: 
Figura 1: Três categorias de desenho biomimético a partir da: forma, função, processo ou sistema.

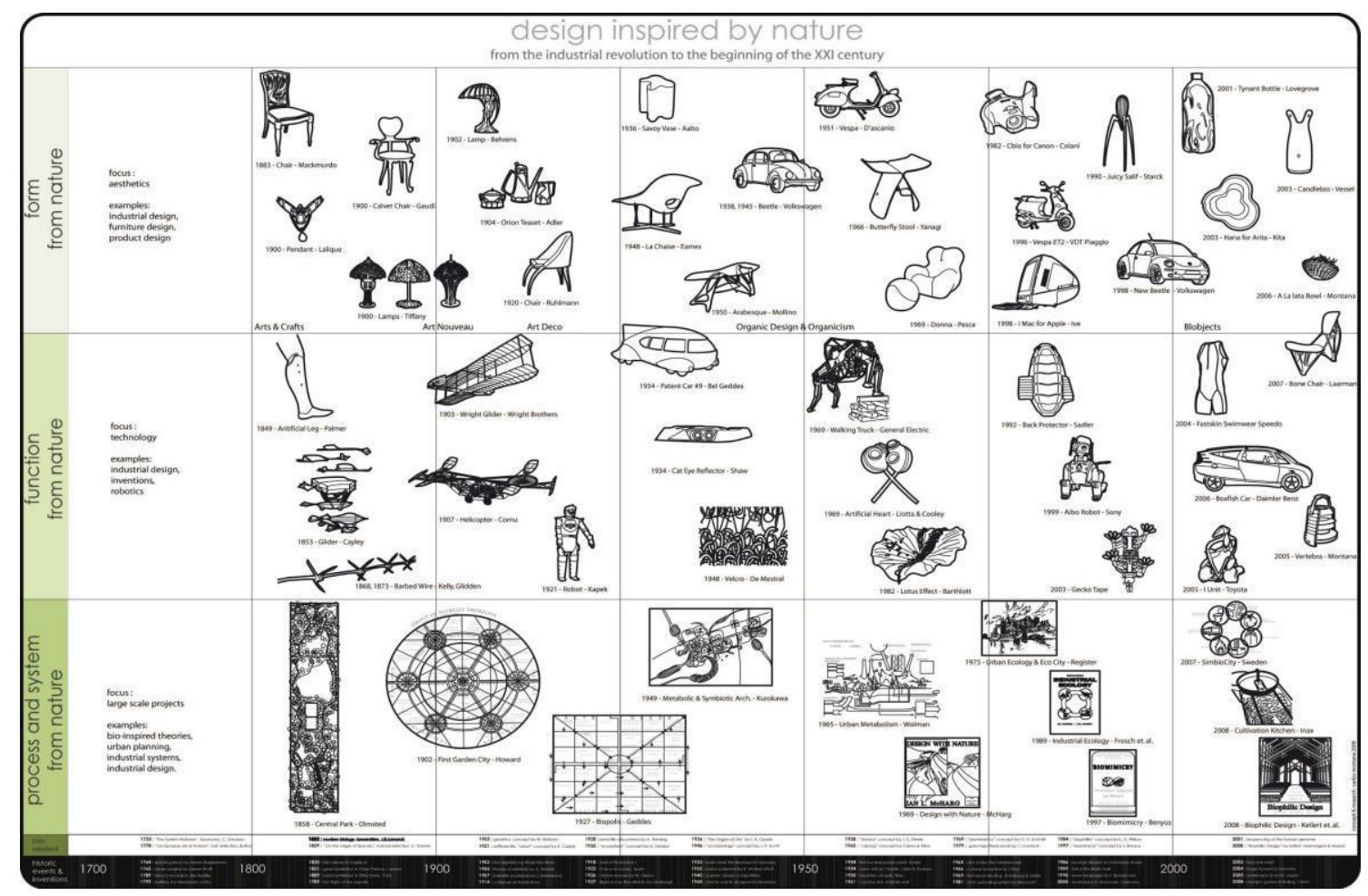

Fonte: Concept ans research - Carlos Montana 2008 - www.bioInspired.sinet.ca

Em outro extremo do avanço dos conceitos de Biomimética, encontra-se a substituição de materiais convencionais por materiais inovadores e biológicos. O bioconcreto, tijolos biológicos e isolante de micélio, que utilizam bactérias ou fungos, são exemplos desses materiais que, além de utilizarem de processos e matérias primas naturais, procedem como materiais mais conscientes, sustentáveis e orgânicos, e, no caso do isolante de micélio, auxilia no conforto acústico.

\section{OBJETIVOS}

\subsection{Objetivo Geral:}

Compreender de que maneira a Biomimética, incorporada à arquitetura e ao design de interiores, pode ser integrada à construção do espaço acadêmico, e de que modo ela pode impactar beneficamente o ambiente, visando a melhoria da produtividade e da criatividade dos usuários do local, através da adequação às suas necessidades físicas.

\subsection{Objetivos Específicos:}

- Fazer um levantamento (programa) das necessidades dos usuários, analisando as possibilidades de mudança para o ambiente;

- Fazer o levantamento dos laboratórios, bem como analisar o espaço e os materiais disponíveis para os pesquisadores do IntechLab;

- Aplicar soluções, através do uso da metodologia Biomimética, considerando seus conceitos e ferramentas, como ergonomia, conforto lumínico e materiais biológicos e orgânicos; 
- Produzir e apresentar um projeto de revitalização, com as possíveis soluções para os problemas apresentados, através da implementação da Biomimética.

\section{PROCEDIMENTOS METODOLÓGICOS}

Utilizando como apoio teórico os autores especialistas na ciência Biomimética, suas aplicações e autores que dissertam sobre conforto e ergonomia, foi, inicialmente, conduzida uma pesquisa teórica com a intenção de compreender como esses mecanismos podem ser aplicados para revitalizar ambientes.

O cenário de estudo foi o IntechLab e os sujeitos da pesquisa os usuários do local. Com isso, foi realizado o levantamento fotográfico da disposição dos laboratórios do IntechLab, bem como dos equipamentos e materiais do local. Também foi feito, através de reuniões, o levantamento do perfil dos usuários do espaço bem como de suas necessidades quando da utilização do espaço.

A partir dessas informações, foi realizado um diagnóstico das disfunções que o local possuía e precisavam ser adaptadas. Observando processos da natureza e aplicando-os em alternativas para solucionar problemas de estrutura e de funcionalidade do ambiente, foram traçadas soluções Biomiméticas para a otimização do espaço. Após serem decididas as soluções mais adequadas para a readequação do laboratório, foi desenvolvido um projeto arquitetônico para possibilitar a visualização das soluções aplicadas bem como as especificações e instruções para aplicação e adaptações.

\section{RESULTADOS E DISCUSSÃO}

\subsection{Objeto de Estudo - IntechLab}

O laboratório IntechLab desenvolve projetos com alunos e professores de universidades, e procura integrar, em um mesmo local, diferentes áreas de conhecimento. Sua finalidade é desenvolver pesquisas que planejem, desde o teste de materiais ou criação de protótipos, até o descarte consciente dos produtos utilizados. Ele é constituído por um conjunto de laboratórios de tecnologias integradas, envolvendo diversas áreas acadêmicas, como a química analítica e polímeros, mecânica, eletrônica e prototipagem.

Apesar da assimilação de diversas áreas, o IntechLab possui um laboratório direcionado, predominantemente, para a área de bioquímica e outro voltado para a mecânica e prototipagem. Portanto, o local precisa de ambientes individuais destinados para cada área, para que sejam desenvolvidos os testes e criados seus protótipos de forma organizada e segura. Porém, também é necessário um espaço de integração para seus usuários, devido à necessidade de estabelecer reuniões entre os grupos de todas as áreas.

\subsection{Proposta}

A partir das reuniões realizadas com seus usuários, e dos levantamentos das necessidades do espaço, concluiu-se que o ambiente deveria passar por uma readequação, redistribuição e integração. Por se tratar de um laboratório que reúne diferentes áreas do conhecimento, foi necessário que um dos ambientes cumprisse o papel de espaço interdisciplinar e que comportasse e atendesse às necessidades acadêmicas do local, no que tange à organização e o conforto durante a condução das pesquisas. Porém, o local em questão possuía inconsistências entre o espaço físico e as necessidades básicas e específicas dos usuários, sendo necessário buscar soluções biológicas, dentro da arquitetura, para as disfunções físicas existentes, que prejudicavam, diretamente, o desenvolvimento das pesquisas. 
Dentro da arquitetura, foi possível encontrar diversas ferramentas, técnicas e materiais que auxiliaram o processo de revitalização do espaço, combinando novas ferramentas com técnicas já utilizadas no ramo da construção, foram encontradas as melhores soluções para que o ambiente fosse reformulado, conforme apresentado na Figura 2.

Figura 2: Associação entre teorias consagradas e formas biológicas na produção do espaço.

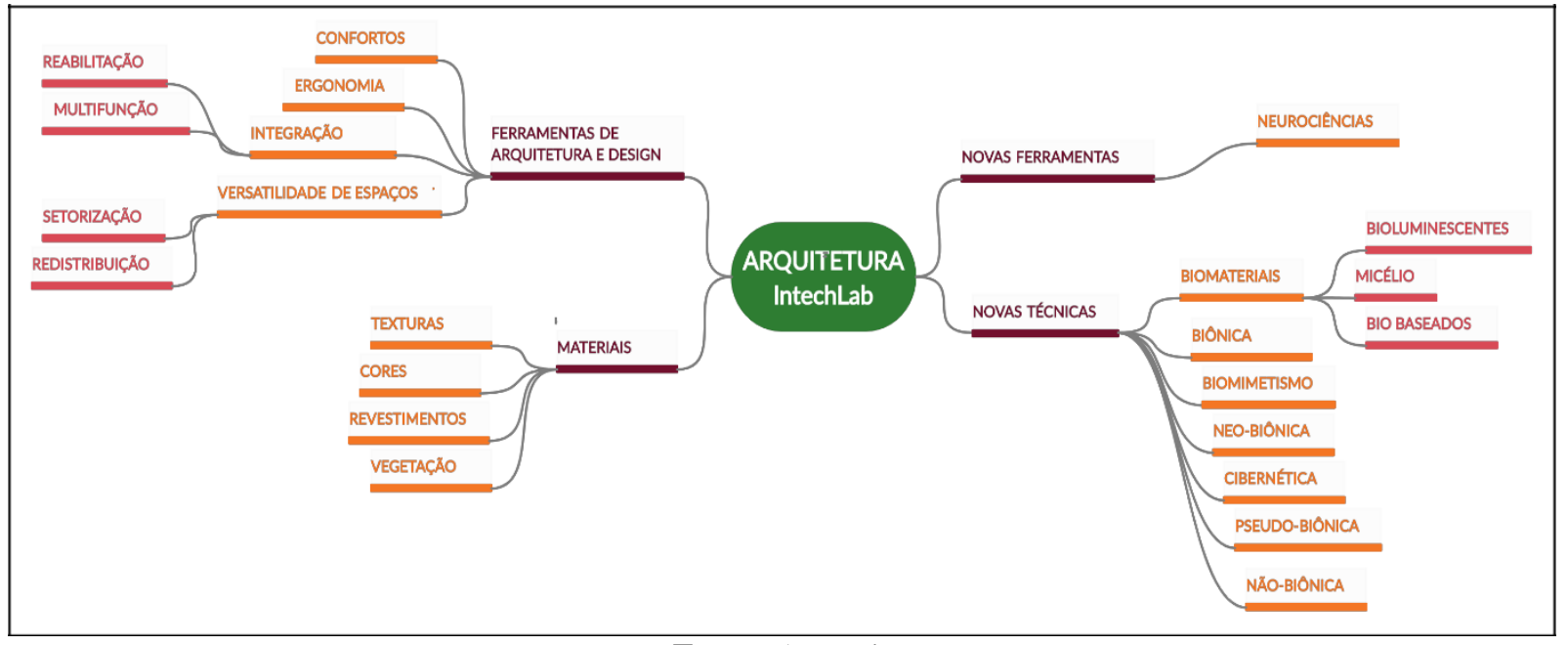

Fonte: Autoral

\section{Readequação}

Para propiciar a readequação do ambiente, foi preciso buscar soluções para os problemas que comprometiam as funções corporais dos usuários, como iluminação, conforto acústico e ergonomia.

No laboratório 1, destinado à química analítica e polímeros, a iluminação natural era insuficiente, uma vez que só havia uma pequena abertura para passagem de luz solar. Porém, mesmo com o uso de iluminação artificial, o ambiente era escuro por causa do tipo de lâmpada utilizada. O laboratório 2, designado à área de mecânica, eletrônica e prototipagem, apresentou o mesmo problema, tendo em vista que um de seus vãos de iluminação era tapado por uma cabine reservada para um equipamento específico, o torno. Desta forma, foi sugerido, em ambos espaços, a troca das luminárias por luminárias mais eficientes que utilizassem o BioLED, aumentando a qualidade lumínica e reduzindo o consumo de energia. A iluminação deve ser utilizada em pontos estratégicos, se adequando às atividades necessárias. No laboratório 1, ela é imprescindível nas bancadas, para manipulação dos produtos químicos, e no laboratório 2, nas mesas de estudo e da oficina de mecânica. Além disso, no laboratório 2 foi necessária a retirada da cabine do torno para aumentar as passagens de iluminação.

Em contrapartida, o espaço de convivência dispunha de uma iluminação excessiva das janelas em alguns períodos do dia, o que atrapalhava o ambiente de estudo. Com isso, foi sugerida a utilização de brises de madeira nas janelas para barrar a iluminação excessiva na parte da manhã, aumentando o desempenho visual do local. Além disso, a implementação de um visor entre o laboratório 2 e o espaço de convivência auxiliaria no aumento a iluminação natural do laboratório.

Quanto às questões acústicas, o laboratório 2 havia uma alta transmissão de ruído pelo equipamento torno, que, mesmo que armazenado com um isolado em um espaço, transmite ruído além do recomendado para ambiente acadêmico. A vista disso, sugere-se a transferência dos equipamentos barulhentos para uma sala isolada, localizada no espaço que era ocupado 
pelo almoxarifado do laboratório 1, com saída para o espaço de convivência, sendo utilizado o isolante de micélio para promover o conforto acústico.

No quesito ergonomia, a bancada do laboratório 1 era inadequada para a manipulação dos produtos, considerando que não dispunha de altura satisfatória e haviam armários na parte inferior, dificultando que os alunos trabalhassem na posição corporal adequada quando sentados, já que não era possível posicionar as pernas embaixo do móvel. Por esse motivo, propôs-se a elevação das bancadas com vidro, para que se tornasse mais ergonômica, permitindo aos alunos manusearem seus objetos de trabalho sentados adequadamente ou em pé e, para isso, também foram adotadas banquetas próprias para laboratório. Com a elevação da bancada com o vidro, permite-se ter um compartimento entre o granito e o vidro onde podem ser armazenados materiais e equipamentos pequenos, auxiliando na organização do espaço.

\section{Redistribuição e Integração}

A redistribuição dos ambientes teve o intuito de sanar as dificuldades quanto à organização espacial e aos móveis e equipamentos, bem como promover uma integração maior no local.

O laboratório reservado para a química analítica apresentava desorganização quanto à disposição dos móveis e máquinas, impedindo a livre circulação no espaço. Além disso, os equipamentos e materiais eram estocados no mesmo ambiente em que as pesquisas eram feitas, devido à falta de espaço. $\mathrm{O}$ almoxarifado, além de se encontrar desorganizado, não tinha espaço suficiente para estocar tudo que precisava ser armazenado decorrente do desuso. Com a finalidade de tornar o ambiente mais organizado e melhorar circulação, propôs-se o reposicionamento de alguns equipamentos e maquinários de grande porte. Por ser um local de manuseio de materiais bioquímicos, deve existir uma facilidade de evacuação caso ocorra algum acidente. Além disso, sugeriu-se a incorporação prateleiras de granito nas paredes, garantindo resistência quanto ao peso dos materiais e equipamentos que ali serão estocados. Com isso, os materiais antes estocados no almoxarifado serão realocados, disponibilizando o local para a colocação do torno. Com essas propostas, foi possível traçar um projeto da redistribuição do espaço, conforme demonstrado pela Figura 3:

Figura 3: Propostas gerais de redistribuição dos Laboratórios.
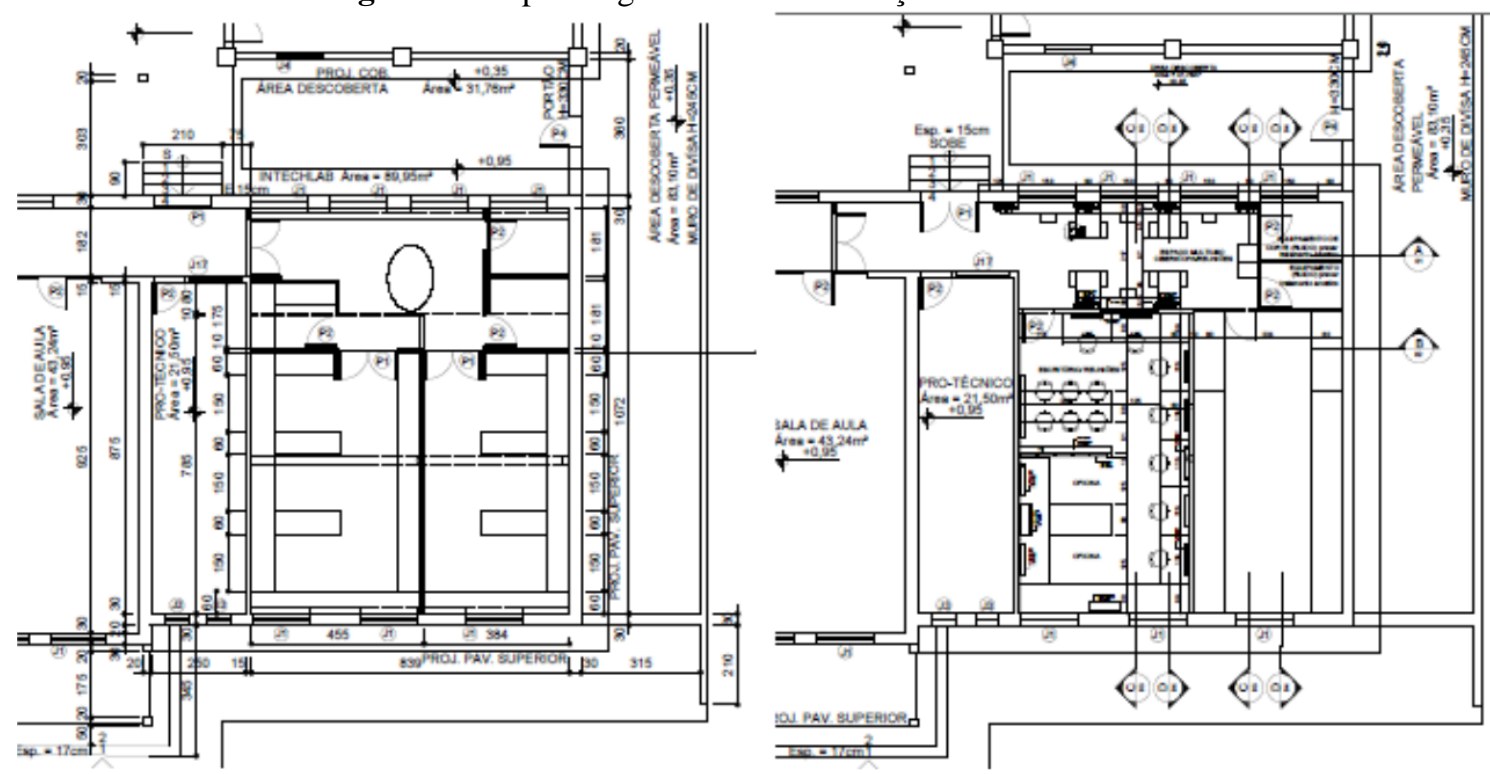

Fonte: Autoral 
O laboratório destinado à mecânica, eletrônica e prototipagem precisava de setorização interna por integrar diferentes ambientes em um mesmo local, como o espaço de reuniões, o espaço da mecânica e dos computadores. Sua organização tornava-o apertado e sua circulação era comprometida. A adequação do mobiliário em dimensões e função foi proposta, eliminando aqueles de características insuficientes ou em desuso, que ocupavam um espaço significativo. Espaços aéreos, sem circulação ou de separação entre ambientes receberam armários para acomodar material e equipamentos.

Foi proposto um espaço de reuniões multiuso, alterando as cadeiras, criando uma mesa de reunião de madeira com tampo de vidro e substituindo o armário que separava os espaços por um painel de madeira, feito com as cruzetas a serem reaproveitadas pelo IntechLab e com sua base e estrutura feita com metalon. Atrás desse painel pode ser adicionada uma estante de madeira e metalon, direcionada para o armazenamento de materiais no espaço de mecânica. Sugeriu-se também a criação de um ambiente de estudo com mesas de computadores e a instalação de prateleiras de metalon e madeira, adotadas para guardar materiais e equipamentos. Seguindo as sugestões apresentadas, foi elaborada uma reorganização do laboratório, conforme a Figura 4:

Figura 4: Redistribuição do Laboratório 2

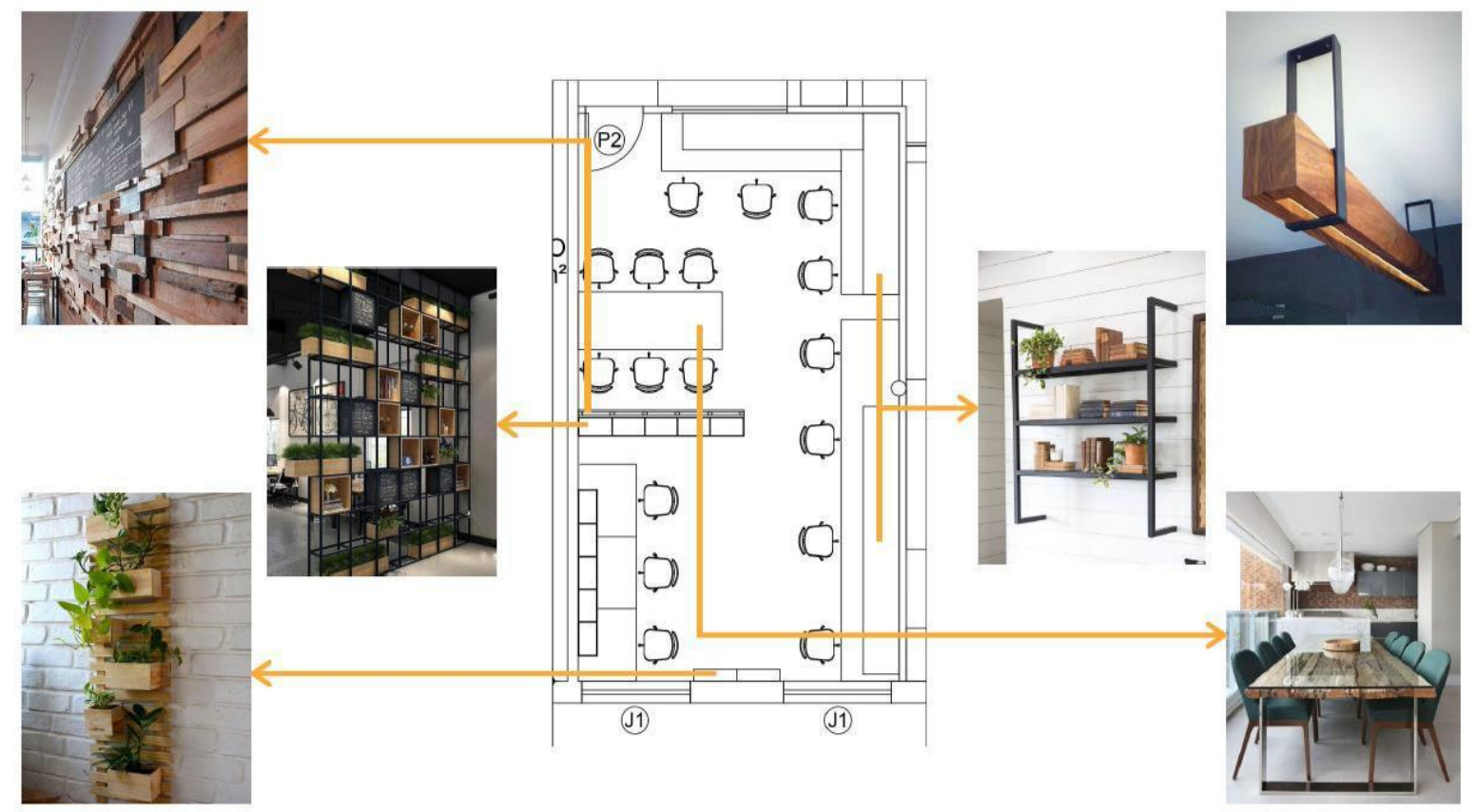

Fonte: Autoral

O espaço de convivência precisava ser readequado para promover a criação de um ambiente mais acolhedor para cumprir a função de ambiente para intervalos de trabalho e que também servisse para que os alunos e pesquisadores pudessem estudar e circular ao mesmo tempo. Foram sugeridas duas propostas para a ordenação desse ambiente, a primeira com a utilização de mesas no formato coworking que ocupariam menos espaço aumentando a circulação e permitindo que alunos estudassem e podendo ser reorganizadas para reuniões gerais das equipes, sendo caracterizado, portanto, como um local de curta permanência, uma vez que um espaço de estudo foi criado no laboratório 2. A outra proposta contava com o uso de uma mesa conjunta que serviria para estabelecer a integração dos usuários, prateleiras de metalon e madeira para auxiliar na organização e calhas para incorporação de plantas nas extremidades da mesa. 
Também fazia parte da proposta a criação de um espaço separado destinado à alimentação ao final do ambiente, com móveis de apoio para café e bancos de espera na entrada para receber visitantes. Visando uma maior integração, foi estruturado um rearranjo do espaço de convivência, de acordo com a Figura 5:

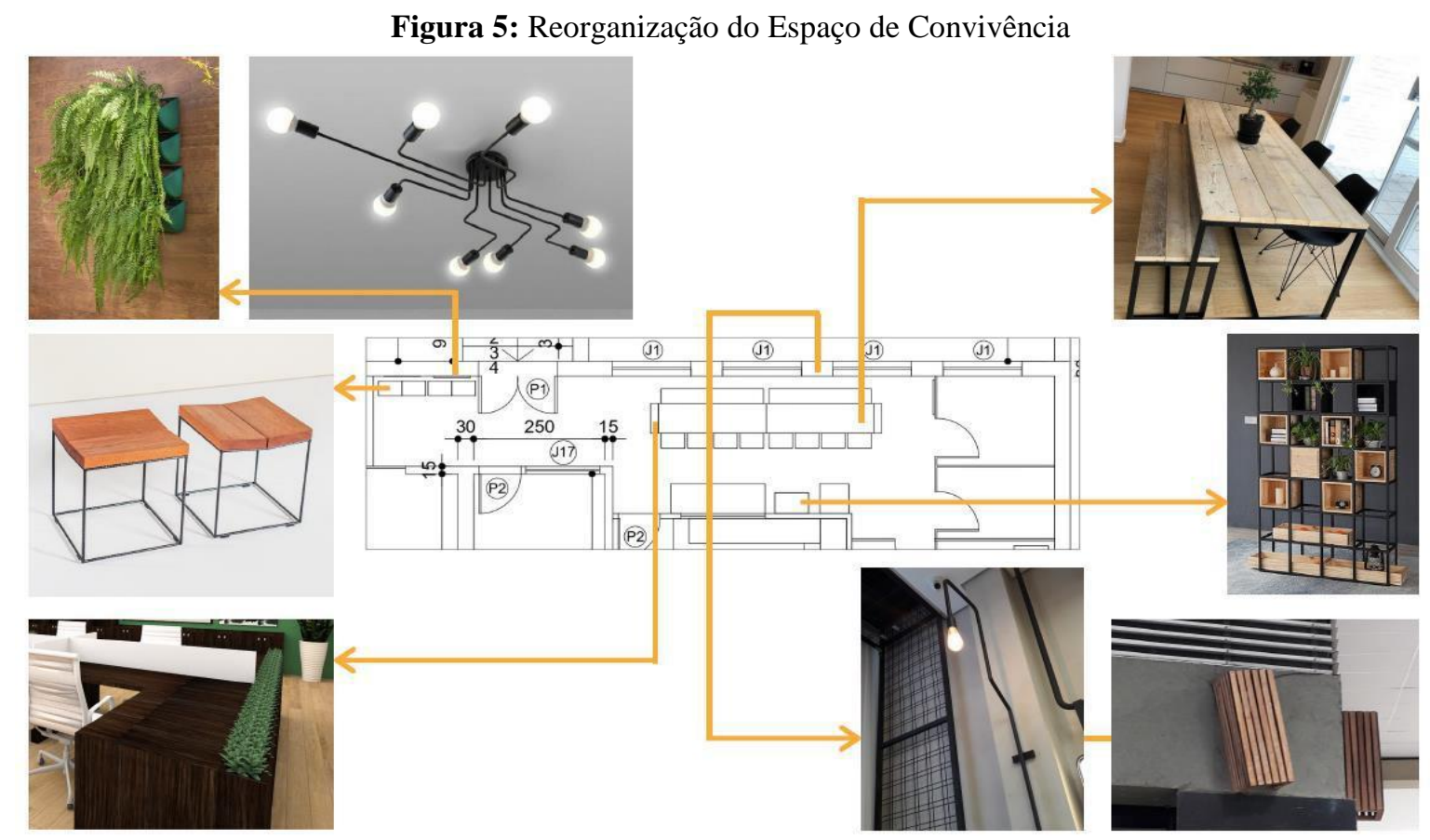

Fonte: Autoral

Em todos os ambientes, foi aplicada poliuréia no piso, para melhorar sua resistência e tornar os ambientes mais claros, auxiliando no conforto visual. Além disso, recomendou-se a incorporação de prateleiras, que possam servir para armazenamento de ferramentas ou materiais mais leves, com jardins verticais para proporcionar uma conexão com a natureza trazendo uma sensação de bem-estar para os usuários do local, em todos os espaços.

\section{CONCLUSÃO}

A tendência ao aumento do número de pesquisas e sua crescente interdisciplinaridade demanda a revitalização dos ambientes acadêmicos. A Biomimética incorporada ao design de interiores permite desenvolver projetos nos quais o ser humano ocupa papel de protagonista. Projetos que apoiam a produtividade intelectual sem deixar de lado funções corporais e processos biológicos resultando no melhor desempenho e reduzindo o adoecimento por stress.

A proposta de uma reorganização harmônica, atendendo ao que os usuários do local desejavam e introduzindo novos padrões de organização de ambientes acadêmicos tem como objetivo a inovação e integração de diferentes áreas do conhecimento tornando o espaço mais seguro e adequado para sua finalidade

Foi possível perceber como conceitos relacionados a arquitetura e edificações, como ergonomia, conforto e iluminação, ao serem vistos a partir da óptica biomimética podem ser traduzidos em soluções que levem em conta o espaço físico integrando a natureza de forma benéfica ao local e às pessoas e de forma não intrusiva resultando em propostas de design interior que além de interativas e versáteis, sejam, também, mais humanas. 


\title{
Agradecimentos
}

Os autores agradecem à Diretoria de Pesquisa e Pós-Graduação do Centro Federal de Educação tecnológica de Minas Gerais (DPPG- CEFET-MG) pela certificação e apoio. Ao CEFET-MG Campus II (Belo Horizonte) e Campus Curvelo pela sessão do espaço físico e ao IntechLab pelo convite, disponibilidade de informações e confiança.

\section{REFERÊNCIAS}

ABNT NBR 10152: Níveis de ruído para conforto acústico. 1987.

BENYUS, J. M. Biomimética: inovação inspirada pela natureza. São Paulo: Ed. 1997.

BIOINSPIRED. The Bio-Inspired Design Landscape. Georgia: Design \& Intelligence Laboratory, Georgia Institute of Technology. 2010. Acesso: https://bioinspired.sinet.ca/content/bio- inspired-design- landscape.

CAVALCANTI, P. B. Qualidade da Iluminação em ambientes de Internação Hospitalar [dissertação]. Porto Alegre: Universidade Federal do Rio Grande do Sul, 2002.

HARKNESS, J. M. The lifetime of connections - Otto Herbert Schmitt, 1913 -1998. Physics in Perspective, v. 4, p.456-490, 2002.

VIDAL, M. C. Introdução à ergonomia. 2012.

WILSON, E. O. Biophilia: The human bond with other species. Cambridge: Harvard University Press, 1984. 157 p.

\section{BIOMIMETICS AS A TOOL IN THE REVITALIZATION OF STUDY AND RESEARCH ENVIRONMENTS: INTECHLAB CASE}

\begin{abstract}
The growth in the production of research in universities, its tendency towards interdisciplinarity and innovation, increased the demand for spaces with a technical profile, but multifunctional and versatile. Biomimicry, which applied to interior design, allows the concept of imitation (mimes) of life (bio) to be expanded to the aspect of the habitat, that is, the support space and contributes to the search for quality productivity. The objective of this work is to present the project investigation, based on biomimetics, of the requalification of the space of IntechLab, laboratory of integrated technologies CEFET-MG, with the demand to combine two aspects of studies, biochemical and prototyping, in a space that promotes the innovation and productivity. From the needs program and the survey, it was possible to prepare the diagnosis. The proposal was outlined, presented and improved from meetings with users, resulting in a project, gradual implementation instructions and specifications. The project is still being implemented, but it was very well received and it is expected to continue the post-occupation evaluation with an analysis of the extent of the impact of applying the biomimetic methodology in offering solutions that, in addition to being interactive and versatile, are also more humane.
\end{abstract}

Keywords: Research Spaces. Biomimicry. Interior Architecture. 